\title{
A CROSS-SECTIONAL MODEL FOR WEST ANTARCTICA
}

by

\author{
B. J. Mclnnes \\ (Meteorology Department, University of Melbourne, Parkville, Victoria 3052, Australia, \\ and Cooperative Institute for Research in Environmental Sciences, University of Colorado, \\ Boulder, Colorado 80309, U.S.A.) \\ and W.F. Budd \\ (Meteorology Department, University of Melbourne, Parkville, Victoria 3052, Australia)
}

\section{ABSTRACT}

The dynamic state of the West Antarctic ice sheet has been termed the grand problem of glaciology. An attempt is presented to assess it by simulating the observed ice thickness and ice velocities along a cross-section from ice stream B (Ross Sea) to Pine Island Glacier (Pine Island Bay) with a numerical model developed from the one described by Budd and McInnes (1978). A kinematic analys is with topographical and regime data from various sources shows the mass fluxes observed near the grounding line of the Ross I ce Shelf to be of the order expected for steady-state balance. Deformation of the ice accounts for only a small fraction of the observed flow there. Simulations (to be described in detail elsewhere) with the Budd/McInnes surging mechanism can approximate the existing ice thickness as a post-surge feature but fail to reproduce the high balance velocities. Both these velocities and the existing ice-thickness profile are simulated successfully as a state of steady sliding, with parameterizations involving the ice thickness above that corresponding to buoyancy and realistically assumed longitudinal strain-rates. A range of results is presented to illustrate the sensitivity of the simulation to changes in various parameters.

\section{INTRODUCTION}

Weertman (1976) has referred to the present dynamics of the West Antarctic ice sheet as "glaciology's grand unsolved problem". Numerical modeling can provide insight into the relation between the various physical features of the ice sheet. Although three-dimensional modeling of the type described by Budd and Smith (1982) and Jenssen (1977) is usually more comprehensive, two-dimensional model ing for ice flow along the cross-section of a flowline has certain advantages. The main one is that reduced computation time makes it possible both to explore a wider range of possibilities for various combinations of unknown factors and to carry out simulations of ice-sheet growth and reaction over the long periods needed to achieve steady states. On the other hand, the two-dimensional modeling requires parameterization of certain three-dimensional effects which need to be re-evaluated if the three-dimensional conditions change with time.

The study here presented has therefore been carried out in conjunction with the three-dimensional modeling of Budd and others (1984) in an attempt to understand some aspects of the dynamics of ice streams and outlet glaciers. Particular emphas is is placed on the dynamics of sliding. Only after this is adequately understood can the questions raised concerning the possible future behavior of the ice sheet (e.g. by Hughes (1973) and Thomas (1976)) be reasonably answered.

Additional impetus for the present study has been provided by the extensive surface and bedrock data in the Scott Polar Research Institute (SPRI) map fol io series described by Drewry and Jordan (1980), and by ice-movement data for the Ross I ce Shelf (Thomas and MacAyeal 1982) and for Pine I sland Glacier (Crabtree and Doake 1982). These new data provided a useful opportunity to test the power of an extended version of the two-dimensional model of Budd and McInnes (1979). Specifically the aim is to provide a dynamic explanation for the existing shape, size and flow regime of the West Antarctic ice sheet through numerical modeling of a representative cross-section, and a general analys is of the fast sliding flow in outlet glaciers and ice streams.

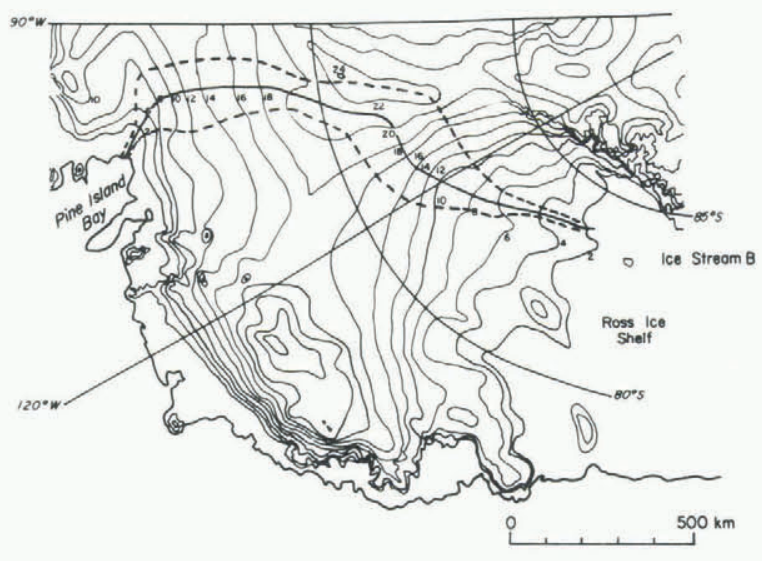

Fig.1. Map of the West Antarctic ice sheet showing surface elevation contours (SPRI map folio), the flow lines chosen for the model, and the estimate of the maximum width of the ice stream (dashed 1 ine). The width ratio from inland bas in to icestream outflow is taken to be $4: 1$. 


\section{DATA SOURCES FOR WEST ANTARCTICA}

For West Antarctica the ice surface and bedrock elevations were obtained from the SPRI map fol io series using map preprints by courtesy of

$G$ de $Q$ Robin and $D J$ Drewry for the region of west Antarctica described by Jankowsk $i$ and Drewry (1981). From the surface elevation map we constructed a continuous cross-section, crossing the divide and flowing into ice stream B in the Ross Ice Shelf (as described by Rose (1979)) on the one side, and out through Pine Island Glacier, a major outflow glacier (as described by Crabtree and Doake (1982)), on the other side. The positions of these flowlines are shown in Figure 1 . Surface elevations and bedrock elevations were read from the maps and interpolated to $20 \mathrm{~km}$ grid intervals. The spacings of neighbouring flowlines going out through the same ice streams were used to obtain an effective ice stream width for three-dimensional parameterizations along the flow line.

Accumulation data were obtained primarily from the compilations of Bentley and others (1964) and Bul1 (1971). I ce temperatures were obtained from Budd and others $(1971,1984)$. The major features along the flow lines are shown in Figure 2.
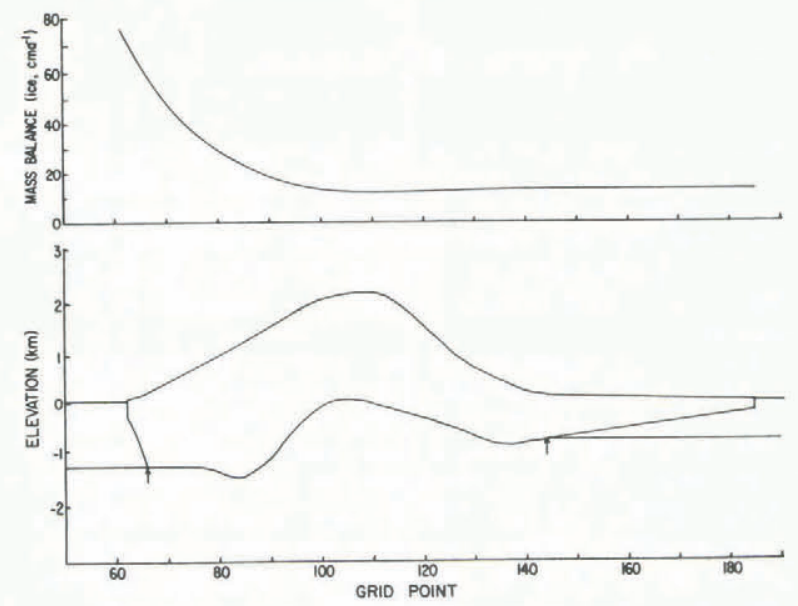

Fig.2. The model cross-section along the flow 1 ines: $P$ ine Island flow line on the left and ice stream $B$ flow line on the right. The upper curve shows the input accumulation profile (ice equivalent) and the lower graph shows the ice-surface elevation and ice-shelf representation and bedrock elevation. The two arrows mark the initial grounding- 1 ine position. The constant grid-point spacing is $20 \mathrm{~km}$.

\section{NON-STEADY STATE AND ICE-SHEET SURGING INVESTI- GATIONS}

Since the main emphas is will be placed on the state of balance and a stable sliding regime, only a brief summary of concurrent surging investigations is given in order to place the possibility of surges into perspective.

The main features of a model of self-surging glaciers and ice sheets have been described by Budd and McInnes (1974), Budd (1975), Budd and McInnes (1978). The extensions required for three-dimensional parameterization for the model have been described by Budd and McInnes (1978). New developments are the inclusion of a variable ice divide and a direct dependence of the ice-flow parameters on the temperature of the ice as a function of distance along the flow line (McInnes 1982).

In surging calculations the model is run for a wide range of the sliding and flow parameters to examine the full range of possible behavior of the ice-sheet model (from dominant deformation flow, to periodic sliding/surging, to steady fast sliding).
Descriptions of these types of flow have been given by Budd and McInnes $(1976,1979)$. Detailed results for the West Antarctic flow 1 ine will be reported elsewhere. Their main features are as follows: (a) the present West Antarctic-Ross basin profile resembles a post-surge or fast-flow profile rather than a pre-surge profile, (b) post-surge model velocities are small and well below those needed to balance the net accumulation upstream, and (c) the ${ }^{\circ}$ fast flow regime tends to be faster, and the crosssection profile thinner, than the present ice sheet.

All these results were obtained for constant external conditions and do not include surge-like reactions to possible sea-level or bedrock changes. It can be concluded that, al though surging and nonsteady flow states cannot be ruled out, the discrepancy between the ice velocities required for balance, as discussed below, and the velocities observed on the Ross I ce Shelf by Thomas and MacAyeal (1982) and on Pine Island Glacier by Crabtree and Doake (1982) make a stable sliding regime close to balance more likely. We therefore consider how this might be modeled to match the observed cross-section shape and velocities.

\section{STEADY-STATE BALANCE}

For each of the flow lines in Figure 1, the ice flux required for steady-state balance has been calculated from the relation

$$
\bar{V} Z=\frac{1}{Y} \int_{0}^{X} A Y d x,
$$

where $\bar{V}$ is the average column velocity at distance $x$ along the flow line (from the summit), $Z$ is the ice thickness, $Y(x)$ is the spacing between neighbouring flow 1 ines at $x$, and $A(x)$ is the accumulation rate. From this relation the "balance velocity" $\bar{V}$ is computed; the results are shown in Figure 3 . Although there is little information on velocity available in the interior, apart from the results near Byrd (Whillans 1979), the flux rates on the Ross Ice Shelf (Thomas and MacAyeal 1982) and Pine Island Glacier (Crabtree and Doake 1982) agree broadly with those shown in Figure 3 and suggest that the ice flow may be close to balance within the error of the data.

In order to understand how a velocity distribution corresponding to zero net mass balance comes about, we will now describe features which are determined from the geometry. The basal shear stress is computed from

$$
\tau_{b}=\rho g(\sin \alpha) Z,
$$

where $\rho$ is the average ice density, $g$ is the gravitational acceleration, and $\alpha$ is the surface slope averaged over several grid intervals. Unlike the balance velocity which increases monotonically from the summit to the floating ice, the basal shear stress increases to about $0.6 \mathrm{bar}$, and then decreases to near zero at the grounding line.

An expression for the contribution of internal deformation to the velocity, which is of the form

$$
\bar{v}_{i}=k_{1} \tau_{b}{ }^{n} z
$$

where $k_{1}$ is dependent on the temperature of the basal layer, has been found suitable for the interior region as the stress increases, but does not explain the fast flow increasing towards the grounding 1 ine. It is therefore concluded that the observed high velocities must be due to the ice sliding.

The empirical ice-sliding studies of Budd and others (1979) indicated that the following type of relation held for the ice-siliding velocity $V_{S}$ in the stable sliding range

$$
V_{s}=\frac{1}{R} \frac{f_{1}\left(\tau_{b}\right)}{f_{2}(N)},
$$


where $R$ is a factor depending on the bed roughness, $\mathrm{N}$ is the normal stress and $f_{1}$ and $f_{2}$ are functions which may be approximated in the simplest form by power relations but with exponents that may change with stress. In this case the functions may be better represented by polynomial functions.

Since the normal stress is related to the excess ice thickness $Z_{\star}$ above the thickness just required for floating (i.e. the buoyancy condition), the values for $Z$ * are also shown plotted in Figure 3 with those of $Z$ along the flow lines. The decrease of $Z *$ towards the grounding line means that the sliding velocities can increase in spite of the decreasing base stress.

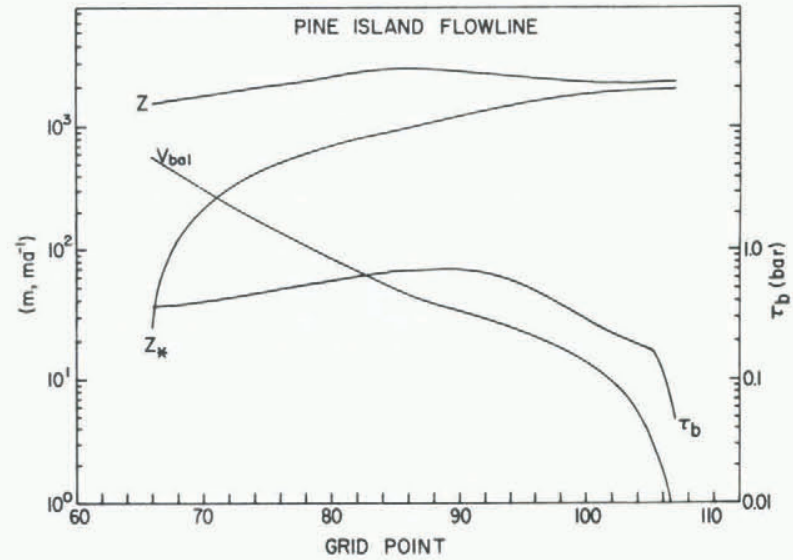

Fig.3(a). Derived geophysical features for the West Antarctic ice sheet cross-section: balance velocity $V_{\text {bal }}(\bar{V})$, basal shear stress $\tau_{b}$, ice thickness $Z$, and ice thickness above buoyancy $Z \star$ for the Pine Island flow line (summit to grounding line of Pine Island Glacier).

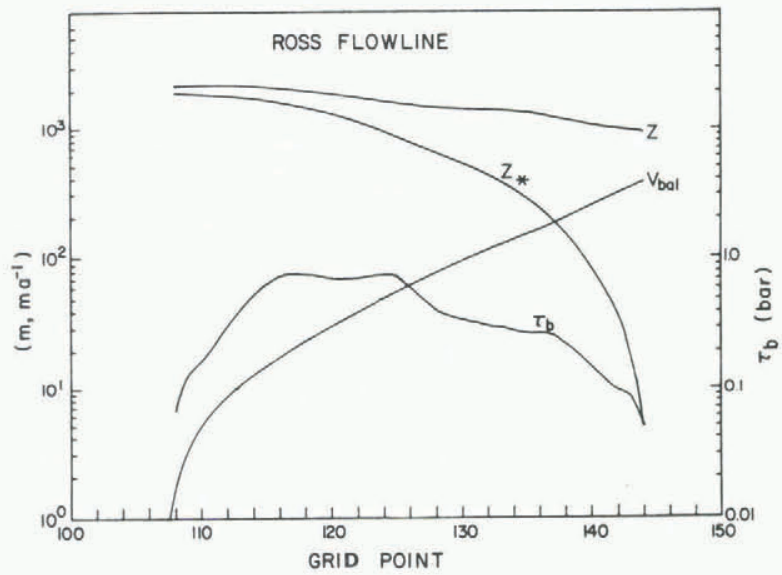

Fig.3(b). Derived geophysical features for the West Antarctic ice sheet cross-section: balance velocity $V_{\text {bal }}(V)$, basal shear stress $\tau_{b}$, ice thickness $Z$ and ice thickness above buoyancy $Z \star$ for the Ross flow line (summit to the estimated position of grounding line of ice stream B).

5. DERIVATION OF ICE-SLIDING AND DEFORMATION PARAMETERS We aim to derive appropriate functions for the sliding relation of the form

$$
v_{s}=\frac{f_{1}\left(\tau_{b}\right)}{f_{2}\left(Z_{\star}\right)}
$$

where at least in the first instance the large-scale average basal roughness is assumed constant.

In order to determine the appropriate functions $f_{1}$ and $f_{2}$, the values of the balance velocity $V$ are

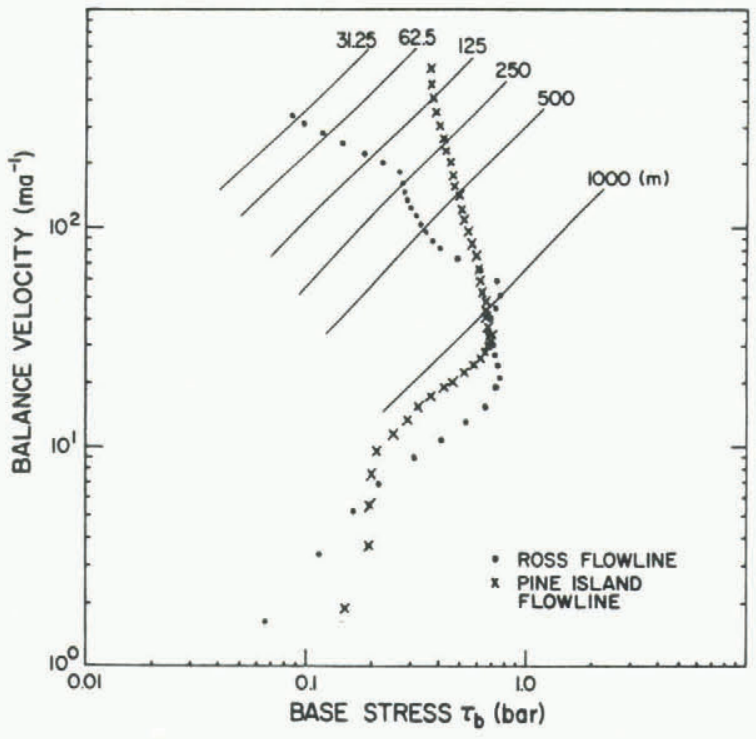

Fig.4(a). Ice-sliding and deformation dynamics implied by present steady-state balance. Plotted are the calculated values of balance velocity against basal shear stress for each grid point along both flow 1 ines: Ross (dots) and Pine Island (crosses). From these values, isolines of $Z *(m)$ (ice thickness above buoyancy) are drawn.

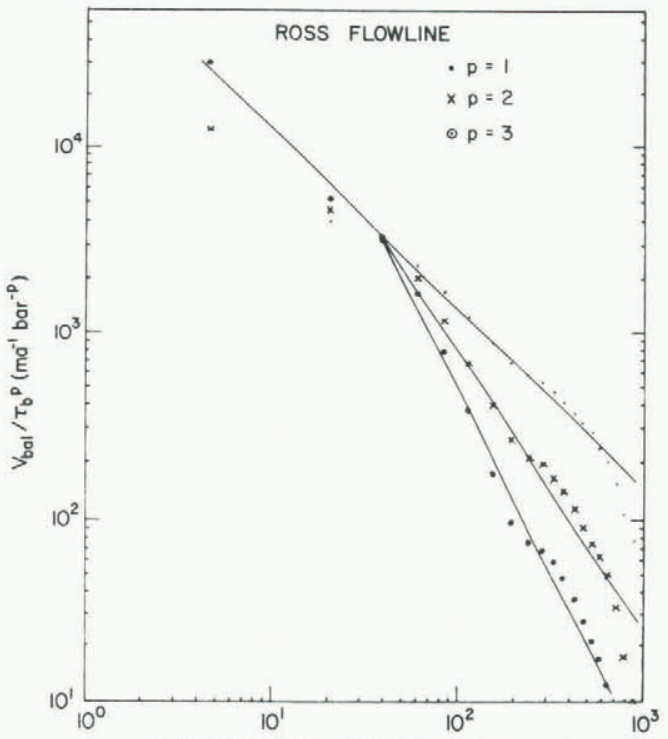

ICE THICKNESS ABOVE BUOYANCY $Z_{*}(\mathrm{~m})$

Fig.4(b). For the Ross flow line computed values of balance velocity over base stress to power $p$ are plotted against the ice thickness above buoyancy for three values of $p(1,2$ and 3$)$. The corresponding line slopes are $1(p=1), 1.5(p=2)$ and $2(p=3)$, where the value of the negative line slope gives an estimate of the $Z$ * power in the stable sliding relation.

plotted against $\tau_{b}$ for various $Z_{\star}$ values in Figure $4(a)$, and $\bar{V} / \tau^{p}$ is plotted against $Z_{\star}$ for various $p$ values in Figure $4(b)$.

These plots suggest that it might be possible to approximate the sliding relation in the high sliding zone (where the deformational component is negligible)

$$
v_{s}=k_{2}\left[{ }^{\tau} b / Z_{\star} q\right]
$$


where $p$ and $q$ are constants. The best fits occur in the range $p=1$ to 3 , and $q=1$ to 2 . Even with these approximations it is difficult to obtain a good fit for both the apparent high sliding speeds near the grounding line and the necessarily slow sliding rates found as far inland as Byrd. A better fit has been obtained by the following relation

$$
v_{s}=k_{2} \tau_{b} /\left(Z_{\star}+Z \star^{2} / k_{s}\right)
$$

where $k_{s}=400 \mathrm{~m}$ and $k_{2} \approx 1-2 \times 10^{5} \mathrm{~m}^{2} \mathrm{bar}^{-1} \mathrm{a}^{-1}$.

This form of sliding relation using a range of values for the parameter $k_{2}$ is used to form a total "dynamics" velocity

$$
\bar{v}_{d}=\bar{V}_{i}+v_{s}
$$

The model of Budd and McInnes (1979), with the extensions described in section 3 , determines this velocity from the geometry of the ice mass for prescribed flow parameters. The steady-state profiles are computed from the mass input, starting from an initial base rock or ice-sheet surface profile and stepping forward in time. The present form of the model permits the sliding velocity to be calculated with either the self-surging or the stable sliding mechanism; all the results that follow have been obtained with the latter (Equation (7)) only.

\section{STEADY-STATE PROFILES FOR STABLE ICE SLIDING}

In order to run the stable sliding model, and to allow it to reach its own steady-state shape and size, it is necessary to include a grounding floating criterion and to have some way of determining the strainrate of the floating ice. For the floating criterion the relation between ice-surface elevation $E$ and ice thickness $Z$ was taken as $E-20=Z / 9$ in meters. This relation gives a reasonable $f$ it to the results for elevation and ice thickness on the Ross Ice Shelf for the thicker ice near the grounding 1 ine determined by Crary and others 1962).

For the ice-shelf strain-rates, two values are prescribed: one at the grounding line $\dot{\varepsilon}_{\text {ga }}$ and the other as an average over the ice shelf $\dot{\varepsilon}_{\text {. }}$. The behavior of the model for a wide range of these strain-rates has been studied. Such a prescription of ice-shelf strainrates (which can be compared with observed values) avoids the problems of having to model the complex iceshelf flow.

The expression for stable sliding velocity requires that $Z \star>0$. In reality, as $Z \star$ becomes small, the ice flow becomes controlled by other stresses such as transverse shear and ice-shelf strain-rates. This behavior has been similarly controlled in the model by using the prescribed grounding-line strain-rate as a maximum strain-rate as $Z$ * becomes small.

For the model runs (stable sliding only) then the key variable parameters are the sliding flow factor $k_{2}$ and the grounding-line strain-rate $\dot{\varepsilon}_{g}$. The deformation flow parameter $k_{1}$ and the ice average iceshelf strain-rate $\dot{\varepsilon}_{\text {se }}$ ares important but have been also studied to establish the sensitivity of the model to a range of values of each.

Because the characteristics of both the Pine Island and the Ross sides of the flow line are quite disparate, the use of different parameters for the different sides was also explored.

Figure 5 shows steady-state profiles obtained by starting from the observed profile and running the model $10 \mathrm{ka}$ forward in time for different values of the set parameters. If the sliding factors or strainrates are set too low, the ice sheet builds up to a large slow flowing form. If the sliding or strain parameters are set too high, the ice sheet thins, retreats and develops a fast flow regime in which sliding is dominant. The profile is rather sensitive to the parameters but it is possible to obtain values which give a close matching to the observed profile.

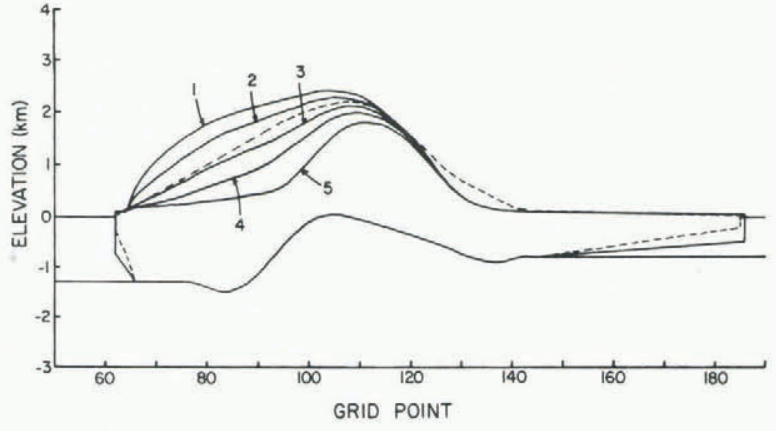

\begin{tabular}{cccc}
$\begin{array}{c}\text { Profile } \\
\text { (a) })\end{array}$ & $\begin{array}{c}k_{2} \\
\left(10^{5} \mathrm{~m}^{2} \text { bar }^{-1} \mathrm{a}^{-1}\right)\end{array}$ & $\begin{array}{c}\dot{\varepsilon}_{\mathrm{g}} \\
\left(\mathrm{a}^{-1}\right)\end{array}$ & $\begin{array}{c}\dot{\varepsilon}_{\mathrm{s}} \\
\left(\mathrm{a}^{-1}\right)\end{array}$ \\
& & & \\
1 & $2.20,1.10$ & $.0030, .0015$ & $.005, .0003$ \\
2 & $2.20,1.10$ & $.0035, .0015$ & $.005, .0003$ \\
3 & $2.20,1.10$ & $.0040, .0015$ & $.005, .0003$ \\
4 & $2.20,1.10$ & $.0045, .0015$ & $.005, .0003$ \\
5 & $2.20,1.10$ & $.0050, .0015$ & $.005, .0003$ \\
\hline
\end{tabular}
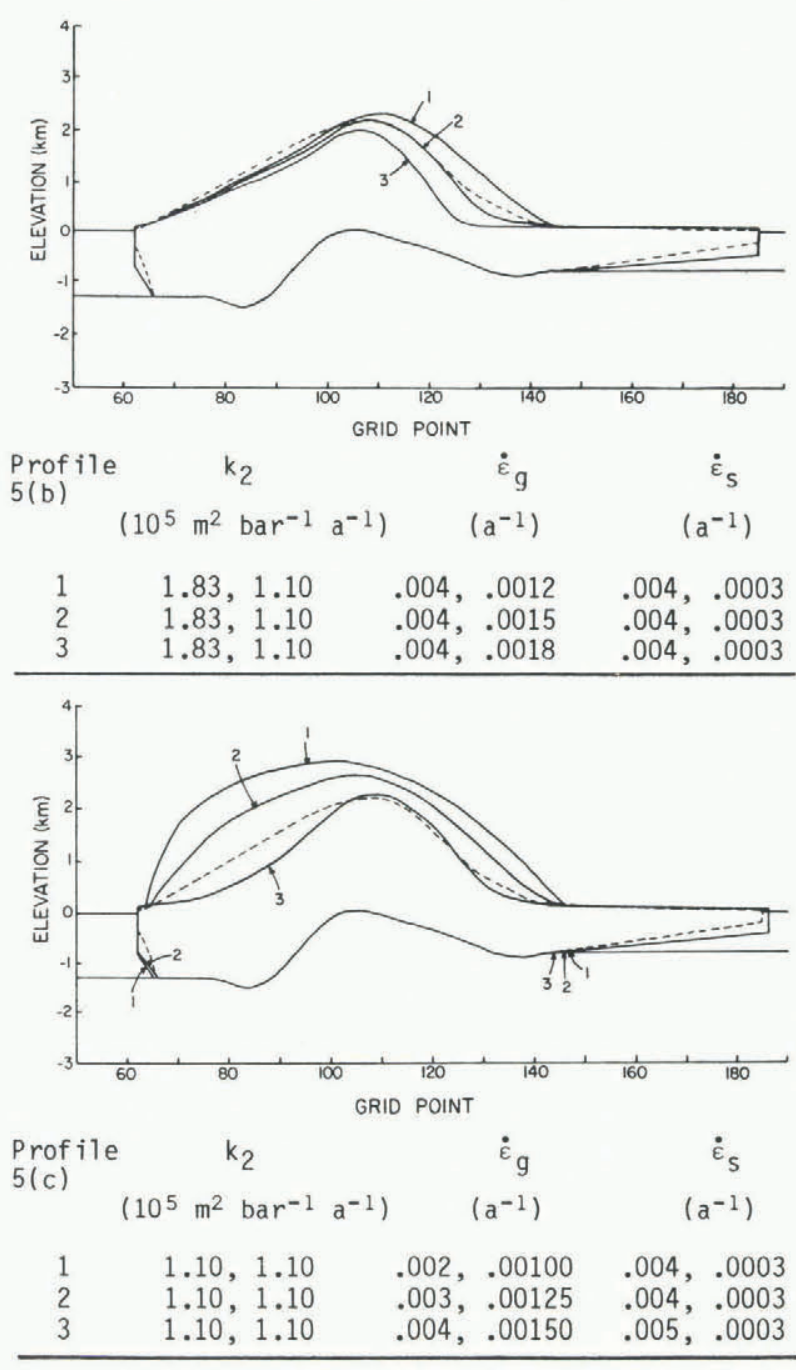

Fig.5. Sensitivity of steady-state ice-sheet profiles to changes in the ice-flow and sliding parameters and in the strain-rates. The parameter values are 1 isted above, and the model growth time was $10 \mathrm{ka}$ starting from the present initial profile (dashed line). Values are given for the Pine Island side first then the Ross side. 


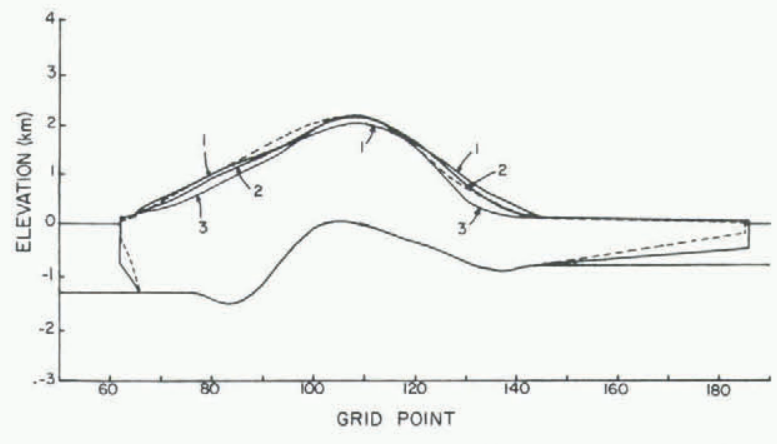

Profile $\mathrm{k}_{2}$ $\dot{\varepsilon}_{g}$ $\dot{\varepsilon}_{\mathrm{S}}$ $\left(10^{5} \mathrm{~m}^{2} \mathrm{bar}^{-1} \mathrm{a}^{-1}\right) \quad\left(\mathrm{a}^{-1}\right)$ $\left(a^{-1}\right)$ 2

$$
\begin{aligned}
& 2.57,1.83 \\
& 1.83,1.47
\end{aligned}
$$$$
1.47,1.10
$$

\section{$.004, .0015$ \\ $.004, .0015$} $.004, .0015$

$.004, .0003$

$.004, .0003$ $.004, .0003$

Fig.6. Final steady-state profiles after a growth time of $10 \mathrm{ka}$ starting from the present ice surface (dashed line), resulting from the model with stable sliding formulation only. The parameter.values for the model are: sliding constant $k_{2}$, strain-rate maximum for grounded ice $\dot{\varepsilon}_{g}$, ice-shelf strain-rate $\dot{\varepsilon}_{S}$. The deformation velocity factor was constant $k_{1}=0.0046\left(b_{a r}^{-3} a^{-1}\right)$ for power law $n=3$, and and $k_{S}=400 \mathrm{~m}$.

For the reasonably close match after $10 \mathrm{ka}$ growth (Fig.6) the following values were used.

$$
\text { Pine Island side Ross side }
$$

$$
k_{1} \operatorname{bar}^{-3} a^{-1} \quad 0.0046
$$

$k_{2} 10^{5}$ bar $^{-1} \mathrm{~m}^{2} \mathrm{a}^{-1} 2.57,1.83,1.47$

$$
\dot{\varepsilon}_{g} a^{-1}
$$

$$
\dot{\varepsilon}_{\mathrm{s}} \mathrm{a}^{-1}
$$

The "close fit" values are similar in magnitude to the results obtained for the three-dimensional modeling by Budd and others (1984), but some differences occur as could be expected for different flowline geometries. The larger strain-rates on the $P$ ine Island side are in accord with the absence of a large ice shelf in Pine.Island Bay; similarly, the larger values $k_{2}$ could reflect the smaller restraint exerted by its free-floating tongue.

It is now possible to study the reaction of the model to a wide range of external changes associated with climate, sea-level or bedrock height. This work is left for a future study but in the interim it may be noted that any additional data on observations of ice velocities and thickness along the outlet ice streams and glaciers can provide further testing of the model.

\section{REFERENCES}

Bentley C R, Cameron R L, Bull C, Kojima K, Gow A J 1964 Physical characteristics of the Antaretic ice sheet. New York, American Geographical Society (Antarctic Map Folio Series 2)

Budd WF 1975 A first simple model for periodically self-surging glaciers. Joumal of Glaciology 14(70): $3-21$

Budd W F, McInnes B J 1974 Modeling periodically surging glaciers. Science 186(4167): 925-927
Budd W F, McInnes B J 1976 A movie film illustrating the numerical modelling of periodically surging ice masses. Melbourne, University of Melbourne. Meteorology Department (Publication 21)

Budd W F, McInnes B J 1978 The periodically surging Medvezhiy glacier matched with a general ice flow model. Matemialy Glyatsiologicheskikh Issledovaniy. Khronika. Obsuzhdeniya 32: 247-260

Budd W F, McInnes B J 1979 Periodic surging of the Antarctic ice sheet - an assessment by modelling. Hydrological Sciences Bulletin 24(1): 95-104

Budd W F, Smith I N 1982 Large-scale numerical modelling of the Antarctic ice sheet. Annals of Glaciology 3: $42-49$

Budd W F, Jenssen D, Radok U 1971 Derived physical characteristics of the Antarctic ice sheet. ANARE Interim Reponts Ser A(IV) Glaciology (Publication 120

Budd W F, Keage P L, Blundy N A 1979 Empirical studies of ice sliding. Joumal of Glaciology 23(89): 157-170

Budd WF, Jenssen D, Smith I N 1984 A threedimensional time-dependent model of the West Antarctic ice sheet. Annals of Glaciology 5: 29-36

Bull C 1971 Snow accumulation in Antarctica. In Quam L 0 (ed) Research in the Antarctic. A symposium presented at the Dallas meeting of the American Association for the Advancement of Science December 1968. Washington, DC, American Association for the Advancement of Science: 367-421

Crabtree R D, Doake C S M 1982 Pine Island Glacier and its drainage basin: results from radio echosounding. Annals of Glaciology 3: 65-70

Crary A P, Robinson E S, Bennett H F, Boyd W W Jr 1962 Glaciological studies of the Ross Ice Shelf, Antarctica 1957-1960. IGY Glaciological Report 6 '

Drewry D J, Jordan S R 1980 Compilation of an Antarctic giaciological and geophysical folio. Polar Recond 20(126): 288

Hughes T 1973 Is the West Antarctic ice sheet disintegrating? Joumal of Geophysical Research 78 (33): 7884-7910

Jankowsk i E J, Drewry D J 1981 The structure of West Antarctica from geophysical studies. Nature 291(5810): 17-21

Jenssen D 1977 A three-dimensional polar ice-sheet model. Joumal of Glaciology 18(80): 373-389

Lingle C S, Hughes T J, Kollmeyer R C 1981 Tidal flexure of Jakobshavns glacier, West Greenland. Joumal of Geophysical Research 86(B5): 3960-3968

McInnes B J 1982 Equilibrium profiles of a cross section through central Greenland. In Radok $U$, Barry R G, Jenssen D, Keen R A, Kiladis G N, McInnes B J 1982 Climatic and physical character istics of the Greenland ice sheet. Boulder, CO, University of Colorado. Cooperative Institute for Research in Environmental Sciences: A 4.1-4.13

Rose K E 1979 Characteristics of ice flow in Marie Byrd Land, Antarctica. Joumal of Glaciology 24 (90): 63-75

Thomas RH 1976 The distribution of $10 \mathrm{~m}$ temperatures on the Ross Ice Shelf. Joumal of Glaciology 16(74): 111-117

Thomas R H, MacAyeal D R 1982 Derived characteristics of the Ross Ice Shelf, Antarctica. Joumal of Glaciology 28(100): 397-412

Weertman J 1976 Glaciology's grand unsolved problem. Nature 260(5549): 284-286

Whillans I M 1979 Ice flow along the Byrd station strain network, Antarctica. Joumal of Glaciology 24(90): 15-28 